\title{
EL WERTHER DE GOETHE: PRECEDENTES LITERARIOS PARA LA CREACIÓN MUSICAL
}

\author{
Luis Acosta Gómez. Universidad Complutense de Madrid
}

\begin{abstract}
La publicación del Werther goetiano supuso un gran acontecimiento no sólo como consecuencia de la revolución que supuso dentro del desarrollo y constitución del género novelesco moderno - de una manera especial dentro de la literatura alemana -, sino también por la recepción peculiar en el seno de la sociedad contemporánea del autor. En el presente artículo de investigación se tratan, pues, las reacciones que la novela produjo a nivel alemán y europeo, reacciones tales que consigo trajeron una oleada de traducciones a numerosos idiomas, recensiones, discusiones públicas, cartas, adaptaciones novelescas, obras dramáticas, poemas, colecciones de cartas, óperas, operetas, sainetes, títeres, obras de ballet y fuegos artificiales, imitaciones, óleos que reproducen figuras y escenas de la novela, porcelanas, etc., y hasta parodias.
\end{abstract}

Cuando Jules Massenet compone su Werther en 1892, que con libreto de E. Blau se estrenaría en Weimar, ha pasado algo más de un siglo desde que Goethe (1749-1832) estableciera los antecedentes literarios sobre los que se fundamenta esta ópera con su gran novela del género epistolar de título Werther, publicada en una primera versión anónima en 1774 y en una segunda en 1787.

La publicación del Werther goetiano supuso un gran acontecimiento no sólo como consecuencia de la revolución que supuso dentro del desarrollo y constitución del género novelesco moderno - de una manera especial dentro de la literatura alemana -, sino también por la recepción peculiar que supuso en el seno de la sociedad contemporánea del autor. Si a ello se añade la influencia que ejerció en otras obras tanto de la literatura posterior como de otras artes, de entre las que la música detenta un lugar especial - el caso de la ópera de Massenet es el ejemplo paradigmático -, nos dará, sin duda, una primera impresión de lo que, en realidad, ha significado la gran obra de Goethe.

La novela produjo dentro del mundo literario una reacción tal que trajo consigo una oleada de traducciones (al francés en 1775, al inglés en 1779, al italiano y al ruso en 1781, al neerlandés en 1790, al sueco en 1796, al español en 1803), recensiones, discusiones públicas, cartas, adaptaciones novelescas, obras dramáticas, poemas, colecciones de 
cartas, óperas, operetas, sainetes, títeres, obras de ballet y fuegos artificiales, imitaciones, óleos que reproducen figuras y escenas de la novela, porcelanas etc., y hasta parodias, de entre las que habría que destacar la titulada Las Alegrías del Joven de Werther de Nicolai, así como, ya algo más tarde, Ultime Lettere di Jacopo Ortis de Ugo Foscolo, Obermann de E. P. de Senancour o Manfred de Lord Byron, por recordar alguno de los ejemplos más conocidos. Las críticas, por otra parte, provenientes de una y otra dirección, seguro que colaboraron también en una gran medida a esa reacción. Desde la crítica negativa aparecida anónimamente (ANÓNIMO, 1775) en que se exige que la obra sea censurada, la solicitud de prohibición por parte de la Facultad de Teología de la Universidad de Leipzig ${ }^{1}$, la crítica de Lessing a la equiparación de puntos de vista éticos y estéticos (Lessing, 26.10.1974), la polémica de Nicolai contra el Sturm und Drang en la parodia a que se ha hecho referencia (Nicolai, 1775), la defensa de Wieland, que no ve en la obra una justificación del suicidio (Wieland, 1774), o las provenientes de autores del Sturm und Drang ( Lenz, 1775 o Schubart 5 de diciembre de 1774), son pruebas más que significativas.

Pero con ser importante, que lo fue, la influencia tanto en el arte en general como en la literatura y crítica literaria en particular, la novela supuso un profundo revulsivo en el seno de la sociedad culta y de una manera especial en círculos de la juventud del momento. La problemática planteada en la obra a nivel de conflicto social, encontrará una aceptación generalizada de la figura, una aceptación de formas y del estilo de vida del protagonista. A su estilo se generalizará la moda en el vestir: frac azul con botones de latón y chaleco amarillo, botas altas de color marrón, sombrero redondo de fieltro, la gente llega a generalizar el uso de un perfume denominado "Agua de Werther", y hasta se llegó a hablar de una ola de suicidios a la manera de la figura de la obra como de la epidemia o enfermedad suicida que invadía por entonces el continente europeo.

Goethe experimentaría en vida el significado de la recepción de Werther. En su obra autobiográfica de casi cuarenta años más tarde Poesía y Verdad (1811-1814), el autor reconoce la tremenda influencia de lo que él denomina el pequeño libro, y piensa que la razón de la misma está en el hecho de haberlo escrito justo en el momento adecuado. Piensa que la quimera suicida no es más que un resultado de la aceptación por parte de toda una generación de jóvenes ociosos de los rasgos del personaje Werther, que identifica en él la propia actitud de protesta $\mathrm{y}$, en definitiva, toda una forma personal de entender la vida; una juventud tranquila en la que se introduce esa quimera ante la falta de actividad de la que participa el propio autor y de lo que precisamente le libera el hecho de escribir la obra.

Efectivamente, la obra incluye elementos claramente autobiográficos, pero como toda obra de literatura, a fin de cuentas de ficción, se constituye en una realidad artística autónoma tanto desde la perspectiva del contenido como desde la configuración artística. Ello es precisamente lo que hace de Werther que se haya convertido en una obra grandiosa y de aceptación generalizada en el tiempo y en el espacio.

El joven abogado Goethe tiene veintitrés años cuando de mayo a septiembre de 1772 realiza prácticas en la Cámara Imperial de la ciudad de Wetzlar, a donde ha acudido, como él diría, deseoso de cambiar la situación en que se encuentra en Frankfurt, donde, después de su examen en Derecho en Estrasburgo, ha ejercido como abogado, y dedicar algún tiempo a su persona, además de, curiosamente, encontrar atractiva, a su vez, la situación peculiar en que se halla la justicia a consecuencia de la mala fama que ha desarrollado debido a la falta de eficiencia. Allí volverá a verse con C. W. Jerusalem (1747-1772), un amigo de sus años de estudiante en Leipzig, y de entre las nuevas amistades que allí establece, contará de una

\footnotetext{
${ }^{1}$ Solicitud presentada el 28 de enero de 1775.
} 
manera especial la de Charlotte Buff (1753-1828) y su prometido el Secretario de Legación J. Ch. Kestner (1741-1800). Durante los tres meses de estancia en Wetzlar, establecen una relación de la que Kestner no podrá ser separado. La relación entre Goethe y Charlotte será apasionada, de tal manera que, por consejo de J. H. Merck, el joven jurista y poeta dejará en septiembre sin despedirse la ciudad y aprovechando una invitación del matrimonio La Roche a pasar unos días en su castillo de cerca de Coblenza, donde conoce a la hija del mismo, la jovencisima Maximiliane von La Roche (1756-1793) por la que Goethe va a sentir una profunda pasión amorosa; Maximiliane se casará en segundas nupcias con P. Brentano. En noviembre volverá de viaje de negocios a Wetzlar donde, hospedado en la casa de los Buffs, recibe la notica del suicidio de Jerusalem, intrincado en las relaciones con un superior, además de en un asunto amoroso, acontecimiento que se agrava, además, por el hecho de que Kestner le ha prestado sus propias pistolas.

Con ello se tienen a disposición los ingredientes autobiográficos que, de una u otra manera, van a encontrar su correspondencia en la realidad de la novela. Con la Lotte de la ficción encuentran similitudes tanto la Charlotte Buff como la Maxe Brentano de la realidad; igualmente Werther, el protagonista de la obra, tiene su correspondencia en $\mathrm{K}$. W. Jerusalem; Albert de la obra se identifica bien con J. Ch. Jerusalem como con P. Brentano; con lo que las correspondencias de los personajes más importantes quedan de esta forma solventadas. Naturalmente no hay dificultades para encontrar similitudes del administrador con el padre de Lotte, de los hermanos de Lotte Hans, Malchen, Mariane y Sophie con Hans, Caroline, Georg, Ammel, Lene, Fritz, Sophie y Wilhlem, Friederike, la hija del pastor, con Friederike Brion, el amor goethiano de Sesemheim, la vieja amiga con Katherine von Klettenberg, la viuda madre de Heinrich con Henriette Bamberger y el pastor de St. con el pastor de Sesemheim.

La personalidad de Jerusalem, con ser importante, ensombrece, con mucho, las respectivas de Charlotte, Kestner etc., tanto en la realidad histórica como en la realidad de ficción en que van a convertirse en la obra. El casamiento de Kestner y Charlotte Buff en abril de 1773 resulta un acontecimiento de segunda importancia en comparación con lo que significó el suicidio de Jerusalem del que Kestner informa con todo tipo de detalles en una carta dirigida a Goethe y fechada el día 2 de noviembre de 1772, exactamente tres días después del suceso - noche del 29 al 30 de octubre -. En ella se patentizan aspectos relevantes de su personalidad. Según la carta, se trata de un hombre del todo insatisfecho y a la vez profundamente enamorado de la esposa del secretario palatino Herd. Apartado siempre de compañías humanas, gusta pasear en solitario a la luz de la luna y se abandona lo mismo a su permanente aflicción que a un amor sin esperanza. Apenas hay una novela que no haya caído en sus manos y que no haya leído, y lo que más le agrada es leer las tragedias más horrendas. Lee filosofía y cavila en todo momento sobre los contenidos que ha leído. Llega incluso a escribir contribuciones sobre diferentes temas, de entre los que destaca uno en el que defiende el suicidio. Se queja sobre las limitaciones que se le imponen al conocimiento humano. Como consecuencia, tal vez, del buen conocimiento que tiene de la filosofía monádica de Leibnitz y en definitiva de la de Spinoza, parece estar convencido de la inmortalidad del alma. A partir de informaciones de amigos, llegó a hacer apología del suicidio, llegando incluso a manifestarse en el sentido de que tenía que ser algo estúpido en el caso de que, después de la decisión, el tiro fallase. En la nota dejada a Kestner le pide obedientemente que le preste sus pistolas para un largo viaje. Tanto es así, que inicia las preparaciones para su objetivo. Más tarde se encontrarían las dos cartas que había escrito. En la primera de ellas se despide de los suyos en los siguientes términos: querido padre, 
querida madre, queridas hermanas y cuñados, perdonen a su desgraciado hijo y hermano; ¡que Dios, Dios, os bendiga! En la segunda le pide igualmente perdón al secretario Herd por la infelicidad que ha traído a su familia, le explica que al principio lo que sentía por su esposa no era más que simplemente afecto y que se marcha con la esperanza de que en la eternidad pueda darle un beso. La carta termina con las con las palabras "Es la una. Volveremos a vernos en la otra vida", después de lo cual parece poder pensarse que es el momento del suicidio mediante un tiro en la cabeza que atraviesa el ojo derecho. Debió ser tal y tan larga la lucha con la muerte que pasarán doce horas hasta que, después de ser encontrado por el sirviente a las seis de la mañana, muera a las doce del mediodía. En la ventana estaba abierto el libro de Lessing Emilia Galotti y junto a él el manuscrito de contenido filosófico de título Sobre la Libertad (Von der Freyheit). Al entierro, que tuvo lugar por la noche del mismo día y cuya comitiva fue precedida por la cruz, no asistió ningún clérigo.

Este es, sin lugar a duda, el acontecimiento que movió a Goethe a escribir la obra Werther, y de él, Jerusalem, la figura que daría personalidad al Werther de la misma, y no tanto su relación con Charlotte Buff, seguro que a un nivel personal apasionada, pero no de naturaleza suficiente como para otorgar la profundidad literaria que logra al final el resultado artístico. La fantasía del autor va mucho más allá de la realidad a que se limita su relación con Charlotte. Lotte y también Jerusalem, convertido en Werther, son el resultado de una manera de entender la literatura en la que ejerce su actividad el genio creador del Sturm und Drang. Lo mismo puede decirse de los cinco días que Goethe estuvo en casa de los La Roche y de los que el conocimiento de Maximiliane sería la ocasión que encuentra el novelista para escribir la segunda parte de la obra. Es, otra vez, el genio creador el que añade y dice la última palabra. Pero eso no lo es todo; en la obra de creación hay todavía algo más; ahí están el desarrollo del código artístico - literario en este caso - y las predisposiciones sociales que lo hacen posible. Todo este cúmulo de presupuestos harán de Werther la obra que en último término realmente es.

Después de dos siglos de andadura de la novela moderna en el sur de Europa, serán la novelas inglesa y francesa las que dominen el panorama narrativo a lo largo del siglo XVIII. Por lo que a la inglesa se refiere, hay que decir que se establece con el objetivo de cumplir la función específica de la advertencia, la educación y la diversión dentro de un ambiente caracterizado por los principios más genuinamente burgueses. Nombres como los de Goldsmith y Richardson dejarán una profunda impronta en el público lector alemán. Con todo, no parece que lo ofrecido por los ingleses satisficiera plenamente la expectativas de los lectores alemanes. No es por ello de extrañar que la aparición de las novelas de Rousseau Nouvelle Heloise y Émile, publicadas en 1760 y 1762 respectivamente, supongan un cambio profundo en la recepción del género novelesco dentro del público alemán. La diversión como momento característico de la novela inglesa cede lugar a las cuestiones y temas de discusión de naturaleza mucho más profunda tratados en las obras del autor francés; por otra parte, se trata de novelas que conmueven y llegan de manera directa al corazón. Porque la solución a las cuestiones planteadas en las relaciones amorosas entre personas de distinta clase social, radica en la consecución mediante el esfuerzo de una posición al nivel de la de mayor alcurnia. Así ha sido siempre en el cuento y así en la novela hasta que Rousseau ofrece la solución consistente no en la adaptación, sino en la búsqueda de un mundo nuevo y distinto, un mundo en el que lo peculiar es la mayor proximidad posible a la naturaleza, lo más próximo a lo que se entiende por natural y dentro de ello, de una manera especial, a lo que dicta el corazón. Que la sociedad del momento esté preparada para esta solución o parte, al menos, de ella, se encuentre identificada con la misma, puede

Odisea, $n^{\circ}$ 2, 2002 
ser la prueba que dé explicación a la gran acogida que experimentó Werther.

Goethe, desde esta perspectiva y los elementos externos de la propia biografía y la de Jerusalem, crea una gran obra y al menos dos personajes grandiosos. Lotte es el personaje femenino de creación goetiana que suplanta al que había dominado hasta entonces la escena de los gustos literarios alemanes, como había sido la Fanny de Klopstock. Porque Lotte es algo diferente; en ella toman forma los principios que van a definir, no mucho tiempo después, muchos de los ideales de la Clasicidad. Es bondad, es belleza, es salud, es naturaleza pura. Hasta el punto de que, si entre los hombres la figura de Werther se convierte en modelo a imitar, las muchachas que han sido bautizadas con el nombre de Lotte, no se sienten portadoras de la personalidad y categorías humanas suficientes como para sentirse dignas de llevar semejante nombre. La personalidad de Lotte es, en definitiva, una personalidad a alabar y a imitar; allí donde va, todo lo que encuentra y la rodea se convierte en su elemento positivo.

Con todo, el personaje que domina y ensombrece al resto por su grandeza literaria, es Werther. Sufre la terrible experiencia de la pasión amorosa de desarrollo y solución desgraciadas por Lotte. Pero con ser un acontecimiento en su vida profundamente negativo, la realidad de la naturaleza de su personalidad radica en que se siente fuera de la sociedad de los humanos, y como, a pesar de todo, cree que en sus cavilaciones llega a comprender la realidad del mundo de una manera adecuada, entiende que no es esa sociedad de seres humanos a lo que se ve enfrentado y contraviene, sino la realidad no natural a la que ésta ha llegado en la conformación de sus circunstancias de vida. $\mathrm{Su}$ corazón le dicta lo que tiene que hacer, y lo que hace es comportarse de una manera distinta a como lo hacen los demás. Vive, viste y come como alguien que se sale de lo normal; y dentro de ese salirse de lo normal está también la circunstancia de no trabajar. Pero como, a fin de cuentas, le resulta necesario hacer algo, ejercer algún tipo de actividad, no encuentra otra ocupación más adecuada que la de dedicarse a sentirse insatisfecho, sin realizar, además, el más mínimo esfuerzo por cambiar la situación. Werther - así se lo comunica a su amigo Wilhelm - vive incialmente en una especie de comunión con la naturaleza, una comunión en que tampoco falta el amor; no obstante, las circunstancias burguesas en que se mueve en la ciudad, se convierten en una limitación a la libertad de su vida, que sólo puede solucionarse con la resignación y, en último término, con la muerte; una salida que le proporciona el consuelo de que puede llegar a ella en el momento en que realice el acto de voluntad necesario. Los acontecimientos se precipitan cuando en un baile conoce a Lotte, lo que provoca en él un estado de embriaguez similar al que le había producido su contacto con la naturaleza, que, con la vuelta de Albert, el prometido de Lotte y representación típica de la racionalidad y moral burguesas, hará que la felicidad se convierta en desdicha. Un último intento por conseguir a Lotte, llevará a la catástrofe.

Lo que, al final, logra Goethe con la genial obra, es construir literariamente en la persona de Werther la realidad del ser humano con todas sus tribulaciones y, aunque pueda parecer que no es así, también con sus alegrías. La obra se convierte en el símbolo de la tragedia de la vida humana dentro de la que no puede faltar el gran acto final que es la muerte, y ello por la sencilla razón de que la muerte es elemento constitutivo de la misma; la muerte se convierte en la verdad de esa vida, independientemente de si, a pesar de todo y aunque no sea esa la intención de la obra, haya voces que se levanten a favor o en contra del suicidio, que, a fin de cuentas, en la obra no es más que un instrumento de construcción artísticoliteraria y, por tanto, un instrumento de manifestación de la forma de libertad absoluta. 


\section{BIBLIOGRAFÍA}

Anónimo, 21 de marzo de 1775. Freywillige Beyträge zu den Hamburgischen Nachrichten aus dem Reiche der Gelerhrtsamkeit. Hamburgo.

Lessing, G. E. 26.10.1974. Brief an Johann Joachim Eschenburg.

Nicolai, F. 1775. Freuden des jungen Werthers. Freuden und Leiden des Mannes. Voran und zuletzt ein Gespräch. Berlín.

Wieland, Ch. M., Diciembre 1774. Der Teutsche Merkur.

Lenz, J.M.R. 1775. En cartas sobre la moralidad del Werther de círculo de amigos de Goethe, Lenz y otros,

Schubart, Ch. F. D. 5 de diciembre de 1774. Teutsche Chronik. 